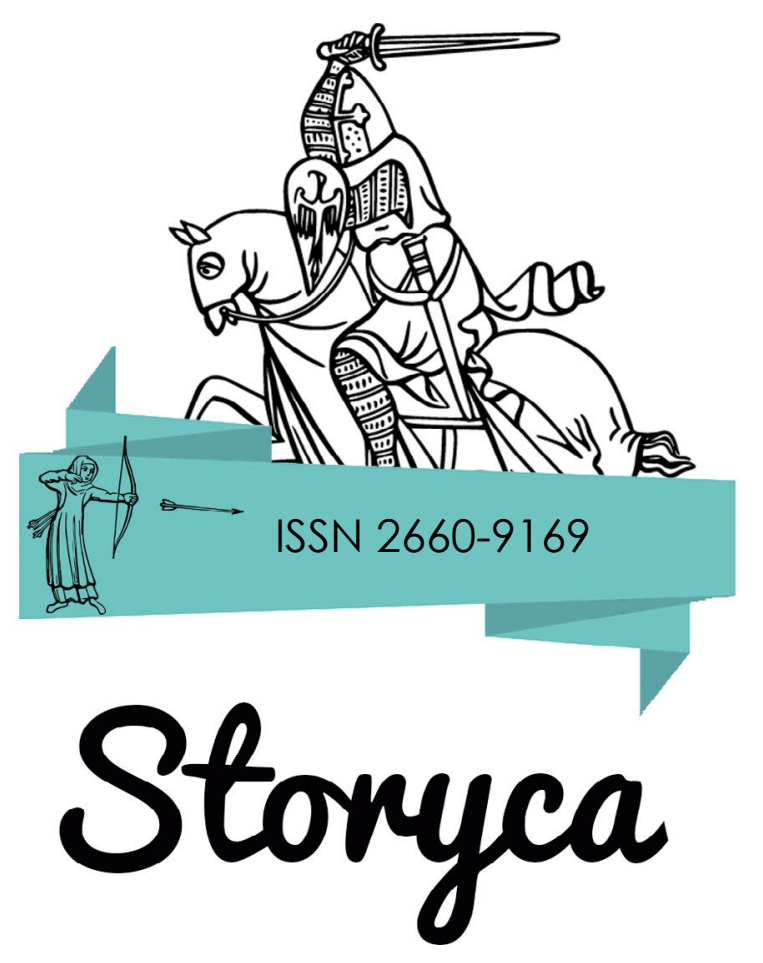

\title{
Amakusa Shirō, la Rebelión de Shimabara y el cristianismo en el manga Makai tenshō (1987)
}

ANTONIO DOÑAS

Universidad Sofía (Tokio)

\section{Introducción}

A finales del periodo medieval de Japón, en uno de los momentos más turbulentos de su historia, llegaron al archipiélago, procedentes de la península ibérica, un pequeño grupo de misioneros encabezados por Francisco Javier. En las décadas siguientes, entre mediados del siglo XVI y el primer tercio del XVII, cientos de misioneros de diferentes órdenes religiosas, estimulados por las noticias que se recibían en Europa, se embarcaron hacia Extremo Oriente con el objetivo de hacer realidad el Japón cristiano soñado por el santo navarro, para quien los japoneses eran «la mejor [gente] que hasta aguora está descubierta») (Ruiz-de-Medina, 1990: 142). Después de casi un siglo de tensas relaciones con las autoridades japonesas, los misioneros, junto con el resto de extranjeros que habían llegado a Japón, fueron expulsados del país; quienes permanecieron allí en secreto o arribaron de manera clandestina a sus 
costas fueron poco después apresados, torturados y ejecutados, en una sistemática e implacable campaña de persecución que acabó en la práctica con el cristianismo en Japón. Esta expulsión fue seguida de un largo periodo de más de dos siglos en los que el archipiélago nipón quedó casi completamente aislado del resto del mundo, hasta que, a mediados del siglo XIX, Japón se vio forzado a abrirse de nuevo al exterior.

Esta presencia de misioneros cristianos en tierras japonesas, que, aunque breve, fue de gran importancia histórica, permaneció muy viva en el imaginario nipón durante el periodo de aislamiento. Los documentos conservados de esa época presentan mayoritariamente una imagen casi diabólica de los misioneros como herejes corruptos que tienen como principal objetivo la invasión de Japón. De acuerdo con este discurso, la decidida actuación del líder del país, el primero de una dinastía que gobernaría Japón durante todo este periodo, lo salvó de una invasión extranjera que habría acabado con sus tradiciones, creencias y valores más arraigados.

Tras la apertura de Japón al resto del mundo, y con la recuperación del contacto directo con el cristianismo, el recuerdo de aquellos primeros misioneros se convirtió en un tema frecuente no solo en la literatura, sino, ya en el siglo $X X$, también en otros medios como el cine, el teatro, el manga, el anime o los videojuegos. En la actualidad, este recuerdo forma parte de un fenómeno más general: en palabras de Rebecca Suter (2015: 1), "Christianity is ubiquitous in [Japanese] popular cultureı. La imagen del cristianismo y de los antiguos misioneros que encontramos en estas obras es compleja y ambivalente, y se vincula en muchas ocasiones con diversos episodios de la compleja relación que Japón ha mantenido con los países extranjeros en época moderna.

En las siguientes páginas voy a presentar brevemente un ejemplo de una obra perteneciente a la cultura de consumo popular de finales de la era Shōwa (1926-1989), el manga Makai tenshō, compuesto por Ishikawa Ken en 1987, en el que encontramos dos de los referentes cristianos más frecuentes en la ficción japonesa moderna: por un lado, la Rebelión de Shimabara, un famoso episodio de la historia japonesa que suele considerarse el canto del cisne del cristianismo en Japón; por otro, el líder de esta revuelta, Amakusa Shirō, uno de los protagonistas del manga de Ishikawa.' El principal propósito de este trabajo es mostrar cómo esta obra, publicada precisamente en un momento de resurgimiento del nacionalismo japonés en las obras de ficción, es en parte heredera de la antigua imagen que de los misioneros y del cristianismo se construyó en el Japón del aislamiento.

\section{El cristianismo en Japón en los siglos XVI y XVII}

El 23 de septiembre de 1543 llegaron a la isla de Tanegashima, al sur de Kyūshū, los primeros europeos que pisaron Japón, dos comerciantes portugueses que

1. En el caso de los nombres propios japoneses, indico primero el apellido y después el nombre, según es costumbre en Japón. Presento los nombres propios y los títulos de las obras solo en rōmaji, sin acompañarlos de los kanjis originales. 
viajaban a bordo de un barco chino. Japón se encontraba en este momento en pleno sengoku jidai ('periodo de los estados en guerra'), un periodo de la historia japonesa en el que decenas de daimyō o señores feudales se disputaron el poder en continuos conflictos bélicos. ${ }^{2}$ Entre mediados del siglo XVI y principios del XVII, tres líderes militares, Oda Nobunaga (1534-1582), Toyotomi Hideyoshi (1537-1598) y Tokugawa leyasu (1543-1616), conocidos como los tres unificadores de Japón, fueron sometiendo progresivamente a todos estos daimyō y unificando Japón. Tras la decisiva batalla de Sekigahara (1600), el poder quedó en manos de la dinastía de los Tokugawa, que dominó el periodo Edo de Japón (1603-1868) en lo que se conoce como el shogunato Tokugawa o Tokugawa bakufu.

Coincidiendo con el ascenso al poder del primero de estos unificadores, Oda Nobunaga, los portugueses establecieron los primeros contactos comerciales con Japón, a los que siguieron poco después, en 1549, los religiosos, al llegar a Japón los primeros misioneros cristianos, los jesuitas Francisco Javier, Cosme de Torres y Juan Fernández. Esto fue el inicio de lo que se denomina en ocasiones "siglo cristiano» (Boxer, 1951) o "siglo ibérico» (Cabezas, 1995) de Japón, durante el cual desembarcaron en el archipiélago decenas de misioneros jesuitas, auspiciados por la monarquía portuguesa, y, más tarde, franciscanos, dominicos y agustinos, amparados por la Corona española. ${ }^{3}$

La fragmentación política de este periodo favoreció inicialmente la extensión del cristianismo, ya que algunos daimyō ampararon a los misioneros en sus feudos con el fin de mejorar sus relaciones comerciales con los portugueses. El propio Oda Nobunaga, en conflicto con diversas sectas budistas, mantuvo una postura favorable hacia los cristianos. Sin embargo, las autoridades japonesas, especialmente tras la llegada al poder de Toyotomi Hideyoshi, cambiaron su posición respecto a los misioneros y, más tarde, respecto a los europeos en general. En 1587 Toyotomi Hideyoshi decretó la expulsión de los jesuitas de Japón, aunque, debido probablemente a su papel fundamental como intermediarios entre portugueses y japoneses, este edicto nunca llegó a aplicarse.

A finales de siglo España implantó nuevas rutas comerciales que conectaban, a través del Pacífico, Nueva España con Extremo Oriente. Con esto no solo terminó el monopolio comercial portugués con Japón, sino también el monopolio de la misión jesuita; en 1593 llegaron los franciscanos a Japón, y poco después, en 1602, les siguieron los dominicos y los agustinos, todos ellos procedentes de Filipinas. Toyotomi Hideyoshi empezó a sospechar posibles intereses colonialistas por parte de los españoles, especialmente tras un famoso incidente ocurrido en 1596: Francisco de Olandía, piloto del galeón

2. Este periodo se extiende a lo largo de tres épocas de la historiografía japonesa, Muromachi (13331568), Azuchi-Momoyama (1568-1603) y Edo (1603-1868), y sus fechas de inicio y fin se sitúan, dependiendo de los especialistas, en 1467, 1490 o 1491 y entre 1568 y 1615 respectivamente. Por otro lado, la imprecisa denominación Japón medieval hace referencia generalmente al periodo entre 1185 y 1603 , año en que Tokugawa leyasu tomó el título de shōgun (Stevenson, 2010).

3. Aunque entre 1580 y 1640 Portugal estuvo integrada en la Monarquía Hispánica, los dos imperios coIoniales continuaron siendo administrados de manera independiente, y las actividades misioneras supervisadas por uno y otro siguieron siendo reguladas a través de sus respectivos patronatos. La bibliografía sobre los misioneros en Japón durante este periodo es muy extensa; además de las obras de Boxer y Cabezas, véanse los panoramas generales de Higashibaba (2001) y Üçerler (2018). 
San Felipe, aparentemente afirmó frente a las autoridades japonesas que las misiones cristianas eran con frecuencia una avanzadilla de una posterior invasión militar española. Apenas unos meses después de este incidente, a principios de 1597, Toyotomi Hideyoshi crucificó en Nagasaki a seis misioneros franciscanos y veinte cristianos japoneses, conocidos como los 26 mártires de Japón.

A principios del siglo XVII, el ascenso al poder de Tokugawa leyasu tras la muerte de Toyotomi Hideyoshi y la llegada a Japón de los ingleses y los holandeses alteraron sustancialmente el panorama. A través de dos edictos, de 1612 y 1614, Tokugawa leyasu ordenó la prohibición definitiva del cristianismo en Japón. En las siguientes dos décadas, el cristianismo fue prácticamente erradicado de Japón y la mayoría de los misioneros fueron expulsados del país. Sin embargo, algunos permanecieron en él de manera clandestina, mientras que nuevos misioneros, así como algunos de los expulsados, siguieron entrando a Japón secretamente en los años posteriores. Esto dio lugar a una persecución más intensa y sistemática por parte de las autoridades japonesas, y muchos de estos misioneros fueron capturados y martirizados. La mayor parte de los cristianos japoneses acabaron apostatando, aunque algunas pequeñas comunidades cristianas localizadas en regiones remotas, los llamados kakure Kirishitan ('cristianos ocultos'), conservaron su fe en secreto durante siglos.

El último capítulo de la presencia cristiana en Japón en el siglo XVII tuvo lugar en Shimabara, al noroeste de la isla de Kyūshū, donde, entre 1637 y 1638, tuvo lugar una rebelión contra el shogunato Tokugawa promovida principalmente por campesinos cristianos. Aunque hubo otros motivos, como la excesiva carga fiscal que se había impuesto a los habitantes de la región, un componente fundamental de esta revuelta parece haber sido el descontento de los numerosos cristianos de la zona ante la represión anticristiana del shogunato. Inmediatamente después de sofocar con gran violencia esta revuelta, en 1639, las autoridades japonesas emitieron el último de los decretos que conformaron el sakoku (literalmente, 'país cerrado'): a los japoneses se les prohibió salir del país y los extranjeros tenían vedado el acceso a él, bajo pena de muerte. Los comerciantes ibéricos fueron expulsados, y solo se permitió un limitado intercambio comercial con chinos y holandeses en la pequeña isla de Dejima, en el puerto de Nagasaki. Con ocasionales excepciones, los japoneses vivieron fundamentalmente aislados del resto del mundo durante más de doscientos años, en lo que se conoce como el periodo Edo, hasta que, finalmente, en 1853 una flota estadounidense forzó a las autoridades japonesas a abrir de nuevo el país.

\section{Demonios, curanderos y magos: los padres y el cristianismo en la literatura japonesa premoderna y moderna}

Si bien es cierto que la influencia religiosa de los misioneros en Japón desapareció con el establecimiento del sakoku —si exceptuamos a los 
mencionados kakure Kirishitan-, su impacto en la cultura de Japón durante el periodo Edo fue sin embargo más profundo de lo que tradicionalmente se ha supuesto. A finales del siglo pasado, uno de los principales estudiosos del siglo cristiano de Japón, George Elison, afirmaba respecto a los misioneros en las conclusiones de su obra Deus Destroyed. The Image of Christianity in Early Modern Japan: "Seen in strict terms, the sum of their cultural contribution to Japan was nilı (Elison, 1988: 248). No obstante, en las últimas décadas un buen número de publicaciones han cuestionado esta opinión tradicional. Entre ellas destaca la monografía de Jan Leuchtenberger Conquering Demons. The "Kirishitan», Japan, and the World in Early Modern Japanese Literature (2013), en la que están basadas las siguientes páginas. Leuchtenberger analiza con detalle la imagen de los misioneros y del cristianismo en el contexto político y cultural de la época Edo a través del análisis de una serie de obras anticristianas muy populares durante este periodo. Se centra especialmente en tres narraciones pseudohistóricas: Baterenki, compuesta en la primera o segunda década del siglo XVII, Kirishitan monogatari, impresa en 1639, y Kirishitan shūmon raichō jikki, publicada a principios del siglo XVIII. A continuación vamos a ver someramente el contenido de estas obras y a señalar las principales características con las que se construyó en ellas la imagen de los misioneros cristianos.

El anónimo Baterenki, 'crónica de los padres', es posiblemente el primer texto que relata la llegada de los bateren, tal como se denominaba, en pronunciación japonesa de padres, a los misioneros cristianos. ${ }^{4}$ El texto comienza con una descripción de los siete sacramentos, seguida por la historia de Santa Lucía y el origen de la Iglesia en Roma. El resto de la obra cuenta los repetidos intentos de los papas por entrar en Japón y conquistarlo, desde el siglo VII después de Cristo hasta el siglo XVI, cuando los cristianos, concretamente en 1560, finalmente consiguen alcanzar el archipiélago, se instalan en Nagasaki e inician actividades comerciales y proselitistas. Allí consiguen convencer a un leproso de convertirse al cristianismo con la promesa de curar su enfermedad, cosa que hacen después de su conversión. Después de varios años en Japón, se descubre que el objetivo de los misioneros había sido desde el principio conquistar poco a poco el país y convertir a su obispo en el shōgun de Japón. El final de la obra describe cómo el daimyō Ōmura, que también se había convertido a la religión de los recién llegados, descubre los verdaderos planes de los misioneros, reniega del cristianismo, destruye la iglesia que estos habían edificado en Hataka y los expulsa de sus dominios.

Este breve texto se centra en presentar a los cristianos como una fuerza extranjera que usa la religión y el engaño para conquistar Japón. Para atraer a los japoneses a la nueva religión y hacerlos así más dóciles en la ulterior conquista, usan el comercio, regalos y la curación de enfermedades. No encontramos en esta obra, compuesta probablemente cuando el cristianismo no había sido todavía prohibido en Japón, descripciones de los misioneros ni críticas a su religión, como sí veremos en los siguientes textos. Dos conspicuos elementos en el Baterenki, sin embargo, se repetirán en la mayoría de textos

4. La obra está traducida al inglés por Leuchtenberger (2013: 137-160). 
posteriores: por un lado, el objetivo de los misioneros de conquistar Japón y, por otro, la asociación de estos con la curación de enfermedades.

El segundo de los textos anticristianos mencionados, el también anónimo Kirishitan monogatari ('relato de los cristianos'), se publicó en 1639, precisamente el mismo año en el que se promulgó el último de los decretos del sakoku. ${ }^{5}$ En estas fechas, prácticamente todos los misioneros habían abandonado ya Japón o habían sido martirizados por el shogunato. Es la única de las tres obras mencionadas que se imprimió, primero en 1639 y después, con el título Kirishitan taiji monogatari ('relato de la exterminación de los cristianos') y una serie de extraordinarias ilustraciones, en 1665.

El inicio del texto relata la llegada del primer misionero a Japón, llamado «Urugan Bateren», y cómo, a través de regalos, se gana la confianza de Oda Nobunaga. Los misioneros consiguen nuevos acólitos entre las capas más bajas de la sociedad y entre los enfermos, especialmente los leprosos, a los que curan de sus enfermedades a cambio de convertirlos al cristianismo. A continuación se describe la doctrina cristiana, el arresto y castigo de misioneros por parte de Toyotomi Hideyoshi y un debate entre un cristiano y un monje budista. Más tarde, un converso revela el plan cristiano de conquistar Japón a Tokugawa leyasu, que expulsa a los misioneros y obliga a los cristianos a apostatar. La obra concluye con el relato del origen y el desarrollo de la Rebelión de Shimabara.

Una de las principales diferencias entre Baterenki y Kirishitan monogatari es la grotesca descripción física de los misioneros que aparece en la segunda obra. Merece la pena citar los primeros párrafos del texto, donde se describe a «Urugan Bateren», que puede identificarse con el misionero Organtino Gnecchi-Soldo: ${ }^{2}$

In the reign of Mikado Go-Nara ${ }^{7}[. .$.$] , a Southern Barbarian { }^{8}$ trading vessel came to our shores. From this ship for the first time emerged an unnamable creature, somewhat similar in shape to a human being, but looking rather more like a long-nosed goblin or the giant demon mikoshi nyūdō. Upon close interrogation it was discovered that this was a being called Bateren.

The length of his nose was the first thing which attracted attention: it was like a conch shell (though without its surface warts) attached by suction to his face. His eyes were as large as spectacles, and their insides were yellow. His head was small. On his hands and feet he had long claws. His height exceeded seven feet, and he was black all over; only his nose was red. His teeth were longer than the teeth of a horse. His hair was mouse-grey in color, and over his brow was a shaved spot in the outline of a winebowl turned over. What he said could not be understood at all: his voice was like the screech of an owl. One and all rushed to see him, crowding all the roads in total lack of restraint. And all were agreed that

5. La obra está traducida al inglés por Elison (1988: 312-374).

6. El jesuita italiano Organtino Gnecchi-Soldo (1530-1609) no estaba entre los primeros misioneros en llegar a Japón. Tras llegar al archipiélago se ganó la confianza de Oda Nobunaga, a quien visitó por primera vez en 1577 (Elison, 1988: 476)

7. Emperador (mikado) de Japón entre 1526 y 1557.

8. Nanban, 'bárbaros del sur', fue el nombre que los japoneses dieron a los españoles y portugueses. 
this apparition was even more dreadful than the fiercest of goblins could ever be. His name was Urugan Bateren (Elison, 1988: 321).

En esta monstruosa descripción del jesuita como una criatura que no pertenece al género humano destacan especialmente dos aspectos. En primer lugar, la apariencia física de "Urugan Bateren» se asocia con los animales: no tiene manos o pies, sino garras; sus dientes son más largos que los de un caballo, su voz es como el ulular de un búho. Al describir el encuentro del misionero con Oda Nobunaga, también su ropa lo asocia con un animal, en este caso con un murciélago: «He was dressed in a garment called habito, which looked somewhat like a piece of felt carpet; it was mouse-grey in color, with long sleeves and the skirts slit. Wearing this garment he looked for all the world like a bat spreading its wings» (Elison, 1988: 325). Asimismo, el comportamiento de los cristianos se calificará más tarde como bestial al describir sus hábitos alimenticios: «And, moreover, day and night they eat the flesh of cows, horses, swine, chickens, and meaner yet! Anxious thus to adopt the manner of wild beasts, many became members of their religion mainly for the taste of such food») (Elison, 1988: 337).

En segundo lugar, en el pasaje citado se compara el cuerpo del misionero con el de dos yōkai o demonios del folclore japonés: el mikoshi nyūdo, una especie de duende o demonio extremadamente alto con un largo cuello y apariencia de monje (Leuchtenberger, 2013:50) y el tengu, originalmente un ser mitad humano mitad ave, similar a las sirenas homéricas, que más tarde pasaría a ser representado como una criatura de apariencia humana con una nariz desproporcionadamente larga. La impresión de 1665 del Kirishitan monogatari incluye unas ilustraciones que nos permiten comparar la representación del cuerpo del misionero en esta obra (imágenes 1 y 2) con las representaciones tradicionales de los demonios mencionados (imágenes 3 y 4).

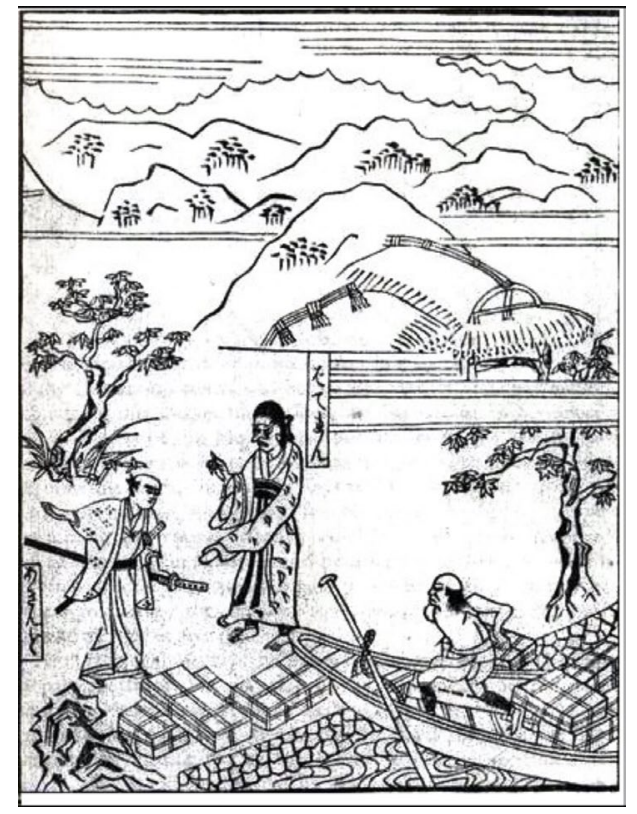

1. Llegada de «Urugan Bateren» a Nagasaki (Kirishitan taiji monogatari, 1665; reproducido en Elison, 1988: 323)

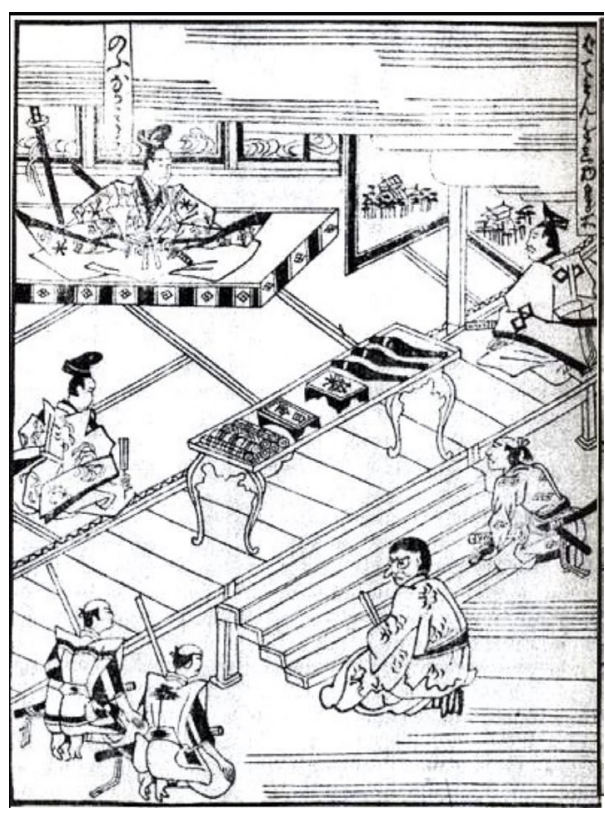

2. Regalos de «Urugan Bateren» a Oda Nobunaga (Kirishitan taiji monogatari, 1665; reproducido en Elison, 1988: 326) 


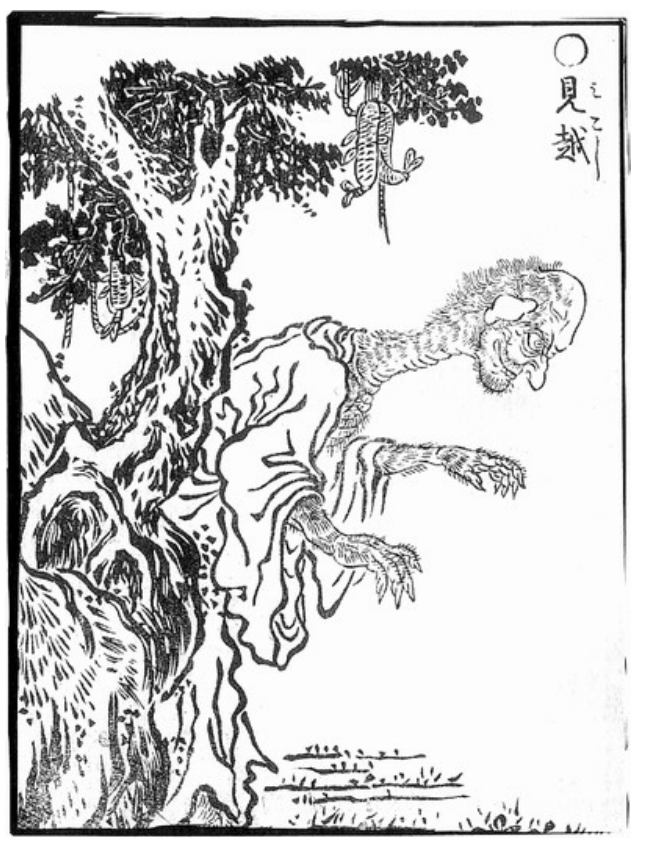

3. Mikoshi nyūdo (Toriyama Sekien, 1712-1788)

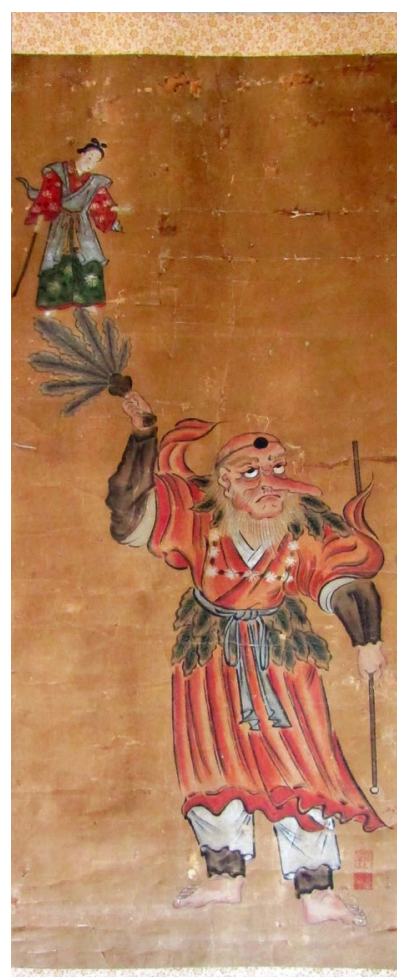

4. Sōjōbō, rey de los tengu (finales del periodo Edo)

En las primeras décadas del siglo XVIII se escribió la que, a juzgar por los más de 150 manuscritos conservados, fue la obra más popular sobre el cristianismo en el Japón del periodo Edo, Kirishitan shūmon raichō jikki ('relato verdadero de la llegada de la secta cristiana'). .9 Aunque hay un buen número de diferencias entre esta y las otras dos obras mencionadas, tanto la historia como los personajes de Kirishitan shūmon Raichō jikki están basados en Kirishitan monogatari.

El texto comienza en la tierra de «Nanban», donde el rey y sus consejeros discuten cómo pueden apropiarse de las riquezas de Japón. Uno de los consejeros advierte al rey de que Japón está protegido por los dioses y no puede tomarse por la fuerza; sugiere entonces que sean enviados a Japón dos hombres versados en magia llamados «bateren» que viven como eremitas en una montaña de la provincia de «Kirishitan». El rey convence a uno de ellos, llamado «Bateren Urugan», para ir a Japón, donde es bien recibido por Oda Nobunaga, que le entrega una extensión de tierra para construir un templo. Poco después se unen a «Bateren Urugan» tres misioneros expertos en medicina, que inmediatamente se ponen a curar a numerosos enfermos japoneses. Los padres, que tienen un espejo mágico en el que los japoneses pueden ver su futura reencarnación, les convencen de que, si se convierten,

9. La impresión de 1665 de Kirishitan taiji monogatari fue detenida por las autoridades japonesas, que en estas fechas empezaron a censurar los libros impresos. Aunque no hubo una prohibición expresa de temas cristianos, parece que los impresores prefirieron evitarlos desde este momento, de manera que no se volverían a imprimir textos sobre el cristianismo hasta la era Meiji (Leuchtenberger, 2013: 68). La más completa de las diversas versiones de Kirishitan shümon raichō jikki, que aparece en los manuscritos con el título de Nanbanji monogatari ('relato del templo de los bárbaros del sur'), está traducida al inglés por Leuchtenberger (2013: 161-198). 
irán tras su muerte al paraíso. Algunos conversos, por otro lado, son elegidos por los misioneros para ser iruman (del portugués irmão, 'hermano'), y son iniciados en las artes mágicas. Tras un debate entre un misionero y un monje budista análogo al que se encuentra en Kirishitan monogatari, Toyotomi Hideyoshi se convence de la falsedad de la secta de los cristianos y los expulsa de Japón. Años después, sin embargo, convoca a su castillo a dos doctores famosos por los extraordinarios prodigios que eran capaces de realizar. Allí, entre otros portentos, invocan el fantasma de una amante a la que Toyotomi Hideyoshi había asesinado. Inmediatamente este se da cuenta de que son dos iruman que han permanecido ocultos, y los manda ejecutar. La obra termina, como Kirishitan monogatari, con un relato de la Rebelión de Shimabara.

La descripción física de los misioneros en Kirishitan shūmon raichō jikki es todavía más monstruosa que en Kirishitan monogatari: miden más de tres metros y tienen la cara verde y el pelo amarillo; además, pueden volar, conjurar espíritus y alterar la materia. La descripción de los misioneros como eremitas que viven en la montaña, por otro lado, remite a otro personaje del folclore japonés, el yamabushi o 'asceta de las montañas'. Originalmente monjes relacionados con la tradición mística y espiritual del shugendō, una especie de religión sincrética originada en el siglo VII, aparecen en la literatura y en la tradición folclórica dotados de poderes mágicos, especialmente curativos. Significativamente, los yamabushi pueden transformarse también en tengu. ${ }^{10}$ En esta obra, además, los nuevos fieles también sufren un proceso de deformación física: el cuerpo de los conversos se cubre con costras, sangre y pus como el de un leproso; de acuerdo con Leuchtenberger, " "the converts' illnesses are attributed to karma from bad behaviour in this life that already represents them as Other within Japanese societyı (2013: 84).

Pero la característica fundamental que este texto añade a los anteriores en la descripción de los cristianos es su asociación con la magia, que se repetirá después en muchos otros textos del siglo XVIII y XIX, especialmente en obras de bunraku (teatro de marionetas) y kabuki." En más de una decena de obras teatrales de este periodo se encuentra un villano cristiano con poderes mágicos cuyo principal objetivo es acabar con el shogunato y hacerse con el poder en Japón. Este villano suele aparecer al principio de la obra como un monje budista, pero más adelante se revela su verdadera identidad; este momento suele ir acompañado de una transformación física que revela también sus poderes mágicos. Invariablemente, en estas obras el villano fracasa en su intento y es asesinado o enviado de vuelta a su país, con lo cual, como interpreta Leuchtenberger, «their plots echo the cycle of penetration and expulsion of a foreign Other whose threat to Japan is disguised by his false identity) (2013: 121).

En algunas de estas obras de teatro, el villano cristiano recibe el nombre de Nanagusa Shirō, en una transparente referencia al líder de la Rebelión de Shimabara, Amakusa Shirō (ca. 1621-1638). No es este el lugar para extenderse

10. Véase el estudio sobre la presencia de yamabushi en el teatro kyōgen, acompañado de diversas traducciones de obras, de Morley (1993).

11. Los misioneros fueron acusados de practicar magia apenas dos años después de llegar a Japón; véanse las referencias en Leuchtenberger (2013: 57). 
con la biografía de este interesantísimo personaje en la historia de Japón que, considerado por algunos de sus contemporáneos cristianos como hijo de Dios, se puso, con apenas dieciséis años, al frente de la mayor revuelta con la que se enfrentó el shogunato Tokugawa en sus más de doscientos años de existencia. ${ }^{12}$ Uno de los pocos objetos que han sobrevivido a la terrible represión de la revuelta por parte del shogunato ha sido la bandera que, de acuerdo con la tradición, Amakusa Shirō ondeó durante la batalla, en la que se lee, en portugués, "Louvado seia o sanctíssimo sacramento» (imagen 5).

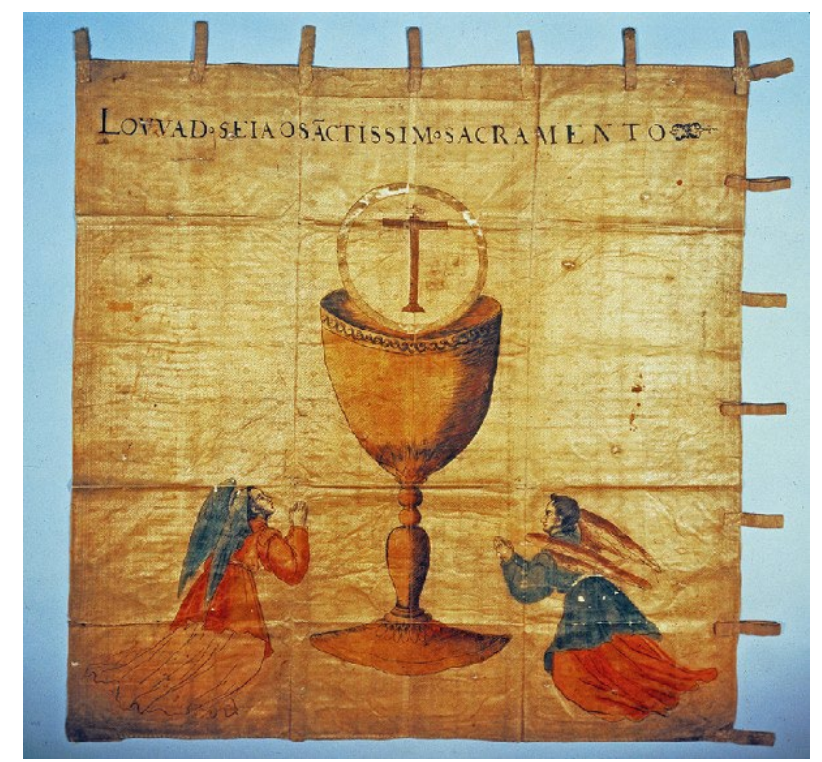

5. Bandera portada por Amakusa Shirō durante la revuelta de Shimabara (1637-1638) y conservada en el Museo Cristiano de Amakusa

La Rebelión de Shimabara y la figura de Amakusa Shirō fueron objeto de innumerables obras durante el periodo Edo, tanto que Leuchtenberger afirma que "Edo-period literature on the Shimabara Rebellion is almost a genre by itself» (2013: 45). La más popular de estas obras fue Shimabaraki ('crónica de Shimabara'), conocida también como Shimabara kassenki ('crónica de las batallas de Shimabara'), Shimabara gun monogatari ('relato de la guerra de Shimabara') o Amakusa monogatari ('relato de Amakusa'), e impresa en numerosas ocasiones entre 1642 y 1708. Otras narraciones sobre este episodio y su líder, con más contenido ficcional, son Amakusa gunki ('crónica de la batalla de Amakusa') y Kinka keiransho ('relatos de tormenta y esplendor'), que incluyen la narración sobre Shimabara de Kirishitan shümon raichō jikki. En estas obras Amakusa Shirō aparece como un villano envuelto de misticismo que es capaz de realizar milagros como, por ejemplo, caminar sobre el agua. Leyendas posteriores describen su origen y su apariencia como híbridos; se le imagina hijo de un bateren y una japonesa y se le describe vistiendo una combinación de ropa occidental y nipona. Algunas leyendas lo presentaron como la versión nipona de una segunda venida de Cristo (Suter, 2015: 113-114).

12. La bibliografía sobre la Rebelión de Shimabara y sobre Amakusa Shirō es muy extensa; remito al capítulo «Amakusa Shirō. The Japanese Messiah» de la obra clásica de Ivan Morris The Nobility of Failure (2013/1975: 107-132). 
La destacada presencia de la Rebelión de Shimabara tanto en Kirishitan monogatari y Kirishitan shümon raichō jikki como en las obras dramáticas e historiográficas mencionadas sugiere que la contienda representó durante la época Edo una especie de epítome o sinécdoque del peligro del cristianismo para el shogunato. Amakusa Shirō, por otra parte, encarnó la naturaleza ambigua y engañosa que se había atribuido a los misioneros en las más tempranas obras sobre el cristianismo. Su personaje, además, se asoció también con la magia, lo cual le permitía transformar su cuerpo al tiempo que se revelaban sus verdaderas intenciones. Podemos observar a través de todas estas obras la creación de un discurso que justificaba y legitimaba la posición de poder del shogunato, que había sofocado brutalmente la rebelión y asesinado a Amakusa Shirō, trasuntos japoneses respectivamente del intento de invasión de los bárbaros del sur y de los misioneros cristianos. Esto añade una nueva capa al carácter ambivalente del joven líder de la revuelta, japonés, pero extranjero en sus creencias, valores e intenciones, lo cual podría también explicar sus frecuentes transformaciones físicas.

Así pues, durante el periodo Edo la imagen del siglo cristiano de Japón se construye en las fuentes japonesas a partir de cinco características fundamentales. En primer lugar, y de manera más destacada, la intención de los misioneros, disfrazada de proselitismo religioso, habría sido en realidad la conquista de Japón y la destrucción de sus tradiciones. En segundo lugar, los misioneros son descritos como criaturas no humanas, más cercanas en su apariencia física y en su comportamiento a los animales. En tercer lugar, estos se asocian con tres personajes del folclore japonés, los yōkai o demonios mikoshi nyūdo y tengu y el yamabushi o asceta de las montañas. En cuarto lugar, los misioneros tienen poderes mágicos: pueden volar, alterar la materia, conocer el futuro e incluso invocar el espíritu de los muertos. En quinto lugar, los misioneros se asocian con la enfermedad y la deformidad física; se destaca su capacidad para curar a los enfermos, especialmente a los leprosos, de entre los cuales seleccionan a muchos de los nuevos adeptos; al mismo tiempo, al convertirse al cristianismo algunos de estos conversos sufren una metamorfosis monstruosa que refleja de manera externa su corrupción interna. Por último, la Rebelión de Shimabara y la figura de Amakusa Shirō funcionaron, por un lado, como representaciones de la pretendida invasión de Japón y de los misioneros y, por otro, como legitimación del shogunato Tokugawa.

Como hemos mencionado en la introducción, el cristianismo es una referencia constante en la literatura, el cine, y otras manifestaciones de cultura popular en el Japón moderno. ${ }^{13}$ Para el estudio de la presencia del siglo cristiano en época moderna contamos con la monografía de Rebecca Suter Holy Ghosts. The Christian Century in Modern Japanese Fiction (2015),14 que postula la existencia de dos diferentes periodos de esta presencia: por un lado, las décadas anteriores a la guerra, que incluyen los periodos Meiji, Taishō y la primera mitad de la era Shōwa, y, por otro, el periodo posterior

13. El periodo moderno de Japón, iniciado por su apertura forzosa al resto del mundo en 1853, se divide en los periodos Meiji (1868-1912), Taishō (1912-1926), Shōwa (1926-1989) y Heisei (1989-2019).

14. Véase también Ota (2000). 
a la guerra, es decir, la segunda mitad de la era Shōwa y el periodo Heisei. La diferente imagen que presentan las fuentes sobre el siglo cristiano en estos dos periodos está relacionada con la compleja relación que Japón estableció con el extranjero durante el siglo XX. En los periodos Meiji y Taishō, tras el redescubrimiento del cristianismo, en palabras de Suter, «a generalized enthusiasm for a newly acquired sense of cosmopolitism was accompanied by deep-seated anxiety about loss of cultural purity as well as creeping nationalist sentiment» (2015: 3). Después de la guerra, el ambiente cultural japonés se movió entre un discurso que destacaba el carácter único y excepcional del pueblo japonés y otro que promovía la internacionalización del país, apoyado generalmente por las políticas gubernamentales.

El siglo cristiano de Japón sirvió como referente para muchos autores para reflejar la complejidad y las contradicciones de la relación de Japón con Occidente durante el siglo XX. Para el primer periodo, Suter estudia con detalle los relatos contenidos en Kirishitan mono ('cuentos sobre el cristianismo'), de Ryūnosuke Akutagawa (1892-1927), donde las relaciones que establecen los misioneros jesuitas y los japoneses en los siglos XVI y XVII sirven como analogía de los sentimientos contemporáneos de curiosidad y deseo, pero también de miedo, respecto a Occidente. Entre 1960 y mediados de los noventa, sin embargo, el miedo y el rechazo a lo extranjero que había caracterizado la representación de los misioneros en el periodo Edo volvió a ser la imagen predominante en la ficción japonesa. En las obras de este periodo, con la obvia excepción de los escritores cristianos, como Shūsaku Endō, autor de la famosa novela Chinmoku ('silencio'), los misioneros son presentados generalmente como personajes negativos y malvados que suponen un grave peligro para la homogeneidad cultural y los valores del pueblo japonés. El papel del manga en este periodo, y especialmente en las décadas de los ochenta y noventa, ha sido caracterizado así por Suter: «The comics' representation of the Kirishitan as the epitome of absolute evil becomes a celebration of Japanese culture as superior to its Western counterpart. This is hardly surprising if we consider how seinen manga was at the forefront of contemporaneous nationalist discourse in the 1980s and 1990sis (2015: 131).

En la representación del siglo cristiano de este segundo periodo tiene un papel central, como también lo tuvo en la época Edo, la Rebelión de Shimabara y la figura de Amakusa Shirō, a los que Suter dedica una parte sustancial de su monografía (2015: 108-168). La identificación que las antiguas leyendas establecen entre el líder de la revuelta y Jesucristo es la base del argumento principal en muchas obras de ficción que tienen a Amakusa Shirō como personaje y que versan sobre su resurrección. De acuerdo con la imagen negativa del cristianismo que encontramos en este periodo, Amakusa Shirō no vuelve a la vida como salvador de la humanidad, sino para vengarse del shogunato Tokugawa por la derrota y la aniquilación de Shimabara. 


\section{El manga Makai tenshō (1987)}

Yamada Fūtarō (1922-2001), uno de los autores más populares de ficción popular en el Japón de la segunda mitad del siglo XX, escribió en 1967 la extensa novela, de más de mil páginas, Makai tenshō ('reencarnación del infierno'). ${ }^{15}$ Esta novela de fantasía histórica está ambientada en el siglo XVII, justo después de la Rebelión de Shimabara, y su trama principal consiste en los intentos de Amakusa Shirō, resucitado gracias a una «magia cristiana» llamada makai tenshō, de derrocar el gobierno Tokugawa y vengar a las víctimas de Shimabara; para ello recibirá la ayuda de varios samuráis legendarios a los que resucita con la misma técnica (Suter, 2015: 120-126). La novela tuvo un extraordinario éxito en su momento, y todavía sigue siendo muy popular, como lo prueban sus tres adaptaciones cinematográficas (1981, 1996 y 2003), ocho adaptaciones teatrales (1981, 2006, 2009, 2010, 201 1, 2013, 2018 y 2021), un anime (1998), dos videojuegos (2003 y 2017) y cinco mangas, obra de los mangaka Ishikawa Ken (1987), Shinzō Tomi (1994), Shōko Toba (1997), Kugo Naoko (2003) y Masaki Segawa (2012). Las adaptaciones de Ishikawa, Shinzō y Masaki pertenecen al género seinen, enfocado a lectores masculinos adultos, generalmente de entre 18 y 40 años, mientras que las de Shōko y Kugo pertenecen al género shōjo, dirigido a lectoras femeninas adolescentes; en los primeros predomina la acción, a veces extremadamente violenta y sangrienta, y los segundos se centran en relaciones románticas homosexuales, dentro del subgénero shōnen-ai.

En las siguientes páginas vamos a repasar el contenido de la primera de las adaptaciones a formato manga de la obra de Yamada, el Makai tenshō de Ishikawa Ken (1948-2006), que, como él mismo explicó en un epílogo publicado en la reedición de 1998 (557-559), pero eliminado más tarde en la de 2005, difiere en tantos aspectos de la obra original que debe considerarse una obra autónoma. El manga de Ishikawa se clasifica, a diferencia de la novela, en el género del terror, y la presencia del cristianismo es aquí más marcada (Suter, 2015: 128).

El manga comienza unos días después del final de la Rebelión de Shimabara, en el castillo Hara, donde los insurrectos se habían atrincherado para resistir los ataques del ejército del shōgun. Allí, Miyamoto Musashi, un legendario guerrero y

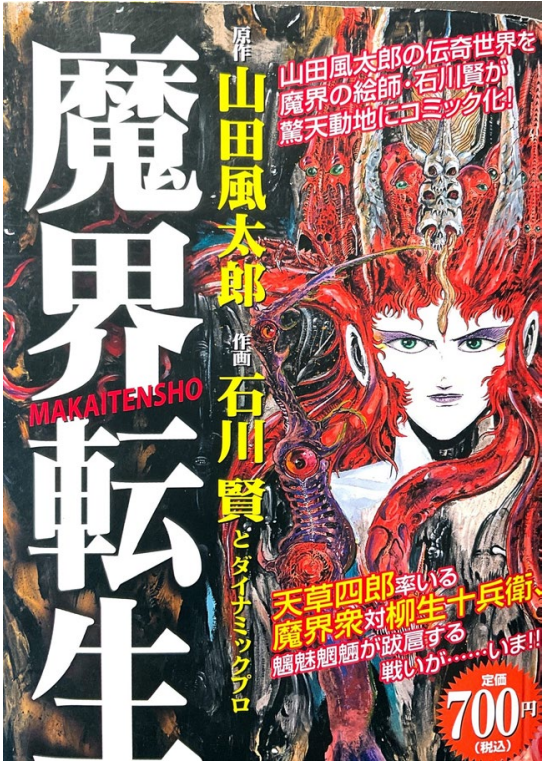

6. Portada de la reedición de 2005 de Makai tenshō filósofo que había participado en la contienda del lado Tokugawa, recorre los alrededores del castillo, donde se acumulan los cadáveres de los rebeldes (imagen 7).

15. Los kanjis de makai, 魔界 ('infierno'), significan literalmente 'mundo (o reino) de los demonios'. 


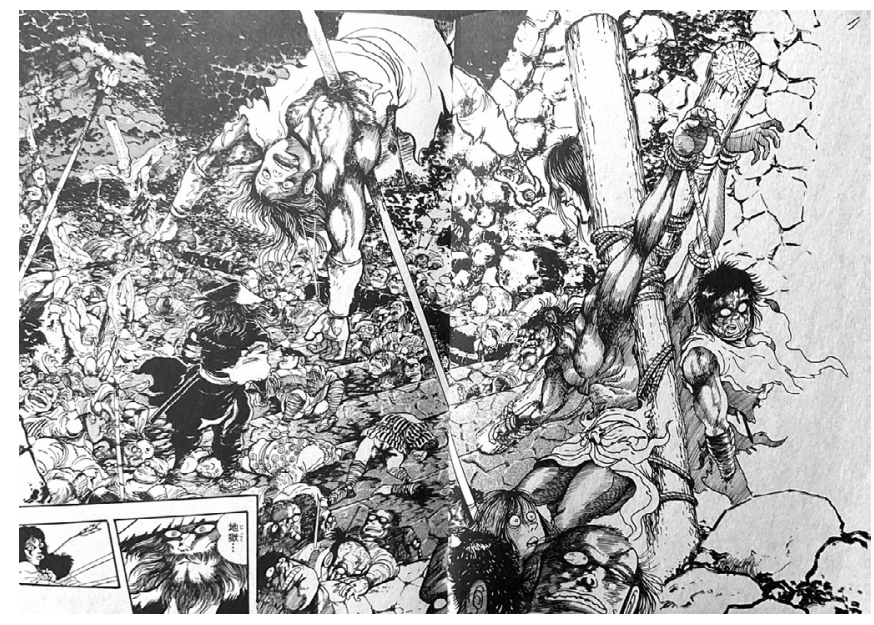

7. Cadáveres de los rebeldes de Shimabara (8-9)

Miyamoto se encuentra con Yui Shōsetsu, otro legendario guerrero, conocido en la historia japonesa especialmente por encabezar otra revuelta contra el shogunato en 1651, la Rebelión de Keian; ambos comentan el desenlace de la revuelta y la muerte de Amakusa Shirō. Un tercer guerrero, llamado Araki Mataemon, también famoso, se une a Musashi y Yui; sin embargo, como Yui señala, Araki había muerto el año anterior. En ese momento aparecen de entre las ruinas una mujer desnuda y un anciano. El anciano es Mori Soiken, uno de los líderes de la Rebelión de Shimabara, que sorprendentemente parece haber sobrevivido. De pronto, el cuerpo de la mujer parece dividirse en dos partes, y de su interior aparece un hombre; es Amakusa Shirō, que ha sido resucitado por Mori, igual que Araki, con el objetivo de derrocar el shogunato, vengarse por la represión en Shimabara y hacerse con el poder en Japón y después en todo el mundo (imagen 8).

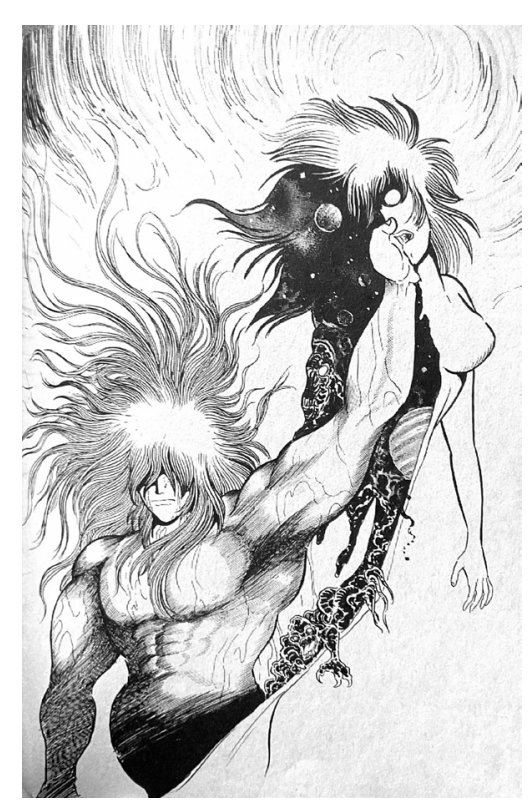

8. Reencarnación de Amakusa Shirō (42)

La narración pasa ahora a Nagoya, donde encontramosa Yagyū Jūbei, otro guerrerolegendario de la época Edo. Yagyū asiste a la resurrección de otro famoso guerrero, Tamiya Botaro, y Yui Shōsetsu, que ha viajado desde Shimabara a Nagoya, le explica el procedimiento mediante el cual todos estos guerreros están volviendo a la vida como demonios: antes de morir tienen relaciones sexuales con una mujer que ha ingerido un dedo de Mori Soiken, y su cuerpo se convierte en el medio por el cual se reencarnan. Yui ha viajado a Nagoya, junto con Araki Mataemon y Hozoin Inshun, otro famoso guerrero también resucitado, para convencer a Yagyū de que se una a los guerreros reencarnados en su lucha contra el shogunato; para ello debe morir y resucitar, lo cual lo convertirá en un guerrero mucho más poderoso y le conferirá la inmortalidad. Yagyū se niega a hacerlo y lucha contra Hozoin, a quien consigue vencer. 
Mientras tanto, Miyamoto Musashi, que siente que está a punto de morir, acepta reencarnarse como demonio y se une al grupo de rebeldes liderado por el anciano MoriSoiken, que promete a Tokugawa Yorinobu, décimo hijo de Tokugawa leyasu relegado a un papel político irrelevante, también reencarnado, el puesto de shōgun después de derrocar al gobierno. El grupo de los rebeldes, por tanto, está formado, además de por Mori Soiken, Yui Shōsetsu y Tokugawa Yorinobu, por Amakusa Shirō y los guerreros Araki Mataemon, Hozoin Inshun y Tamiya Botaro (imagen 9), a los que se unirá Miyamoto Musashi una vez completada su reencarnación.

A continuación, Mori Soiken y Amakusa Shirō explican con más detalle el plan de los rebeldes reencarnados (imagen 10):

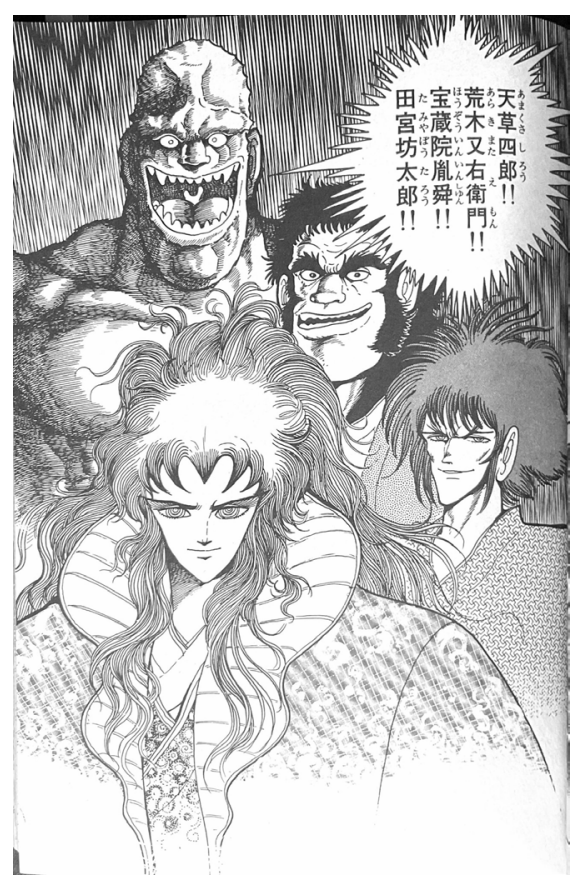

9. Amakusa Shirō (abajo), Araki Mataemon (arriba a la derecha), Hozoin Inshun (arriba a la izquierda) y Tamiya Botaro (a la derecha) (143)

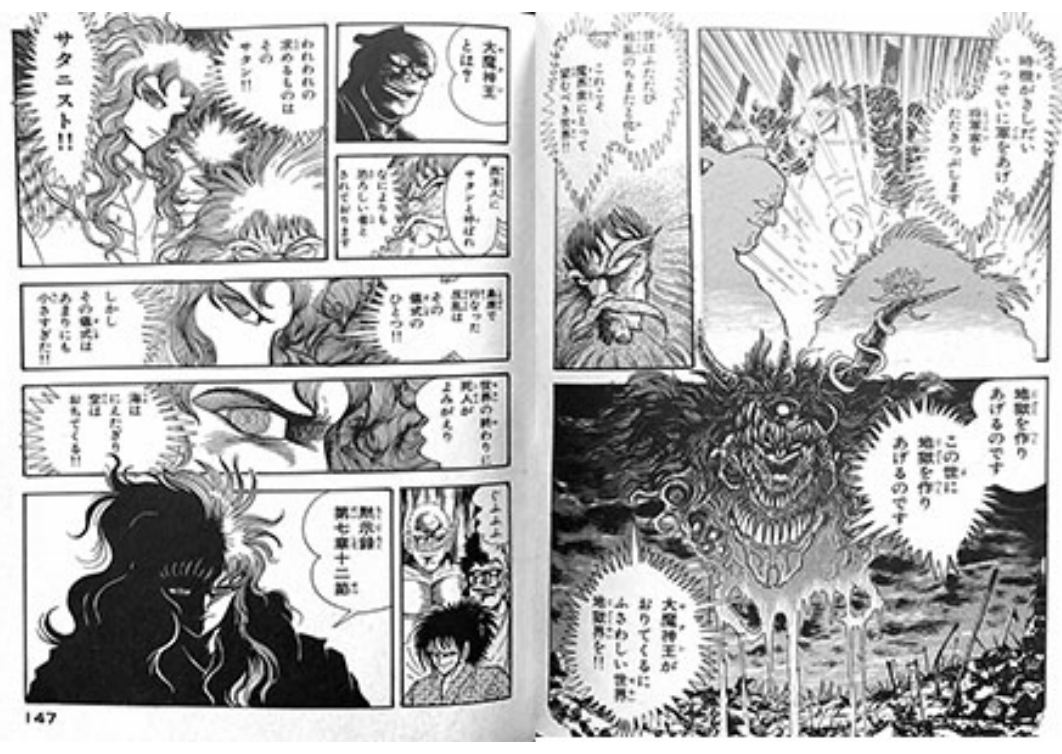

10. Los planes de los rebeldes

[146] MORI SOIKEn: En cuanto surja la oportunidad, levantaremos un ejército y destruiremos la casa del shōgun. El mundo caerá en el caos de la guerra. Este es el mundo que el Demonio quiere. Crearemos un infierno. Un infierno aquí en la tierra. Un mundo infernal para la llegada de Satán. [147] TOKUGAWA YoRINOBU: ¿Satán? ${ }^{16}$

16. En estas dos primeras referencias, Satán se escribe con los kanjis 大魔神王, acompañados del furigana (ayuda para la pronunciación de los kanjis) サタン (satan) en el margen; los dos primeros kanjis, 大魔, significan 'gran demonio' y los dos últimos, 神王, 'rey dios'. A partir de aquí, Satán se escribirá siempre en katakana (サタン), silabario que se emplea usualmente para palabras extranjeras. 
MORI SOIKEn: Satán es el nombre que los occidentales dan al ser más terrorífico que existe.

AMAKUSA SHIRŌ: Nuestro objetivo es Satán. [Somos] satanistas. La destrucción en Shimabara solo fue una ofrenda para él, una ofrenda demasiado pequeña. Al final los muertos resucitarán. Los océanos hervirán y el cielo caerá. Apocalipsis, capítulo 7, versículo 12:17 [148] «Y miré cuando él abrió el sexto sello, y hubo un gran terremoto, y el sol se puso negro como un saco de pelo de cabra, y la luna se llenó toda como de sangreı. Ese día la tierra será juzgada. Ese día será el primero de la era del infierno.

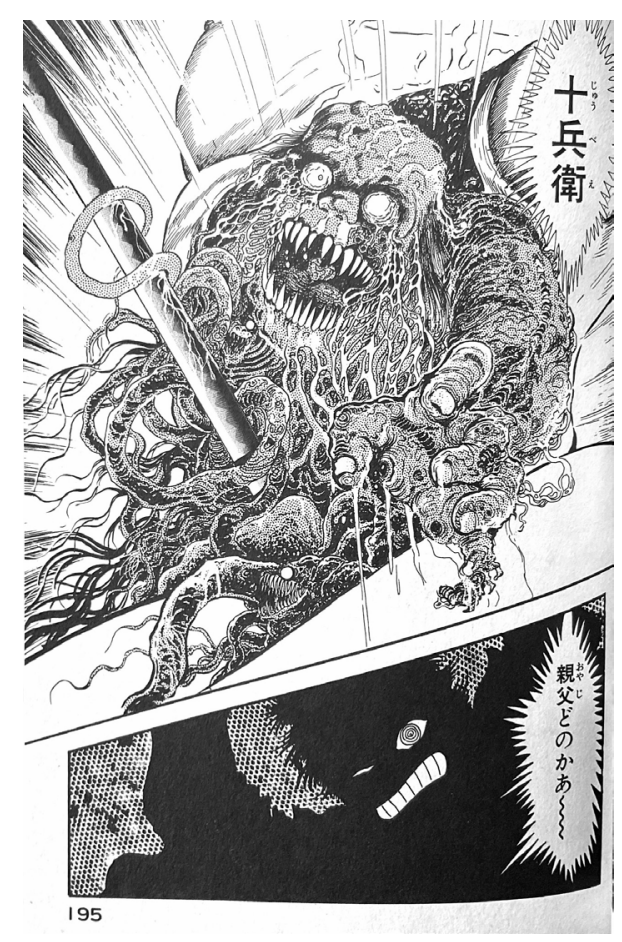

11. Yagyū Munenori, convertido en una criatura monstruosa (195)

A Mori Soiken solo le quedan dos dedos, y por tanto solo puede resucitar a dos personas más; las dos personas seleccionadas son Yagyū Jūbei, a quien esperan convencer para que se una a la rebelión, aunque sea por la fuerza, y su padre, Yagyū Munenori, que está gravemente enfermo. Al conocer la enfermedad de su padre, Yagyū Jūbei va a visitarlo, pero en su lugar encuentra a una hermosa joven. Sospechando lo ocurrido, la ataca con su catana y de su interior sale su padre con una apariencia monstruosa, dado que no ha completado el proceso de reencarnación (imagen 11). Yagyū Jūbei, avergonzado por la decisión de su padre, que no ha querido aceptar noblemente la muerte, lo mata.

Decidido a enfrentarse al grupo de rebeldes, Yagyū Jūbei quiere más información sobre la poderosa magia que ha podido observar con sus propios ojos. Un sirviente de su padre le da una valiosa información (imagen 12):

[175] SiRviente: Señor Jūbei, si realmente has visto todas estas cosas... Creo que sé de alguien que puede saber algo sobre ese infierno del que hablas.

JūBEl: ¿̇Qué?

SIRVIENTE: Aunque la brujería y la medicina occidentales están prohibidas por el shogunato, entre los que practican las artes oscuras, son conocidos desde hace cien años. [176] Combinando las escrituras occidentales con las artes ninja japonesas, llevando a cabo terroríicos experimentos, solo pueden ser obra del Diablo. He oído que los experimentos han dado a luz horribles criaturas; casi todas ellas han acabado mal, y miles de fieles han sido asesinados en el proceso. Algunos de ellos lo consideraron necesario si querían sobrevivir al periodo de los estados en guerra, así que continuaron el estudio de la magia negra y la medicina occidental, y a través de esto se pudo escuchar hablar del infierno y del

17. Hay un error en la referencia; la cita correcta es Apocalipsis 6.12. 
mundo de los demonios. Pero con el tiempo, todos han sido apresados y asesinados. Solo queda uno que practica la medicina occidental y la magia negra. Vive en lo alto del monte Todoroki, en Iga, en un lugar llamado Kukidani; es un lugar al que ni siquiera se acercan los pájaros.
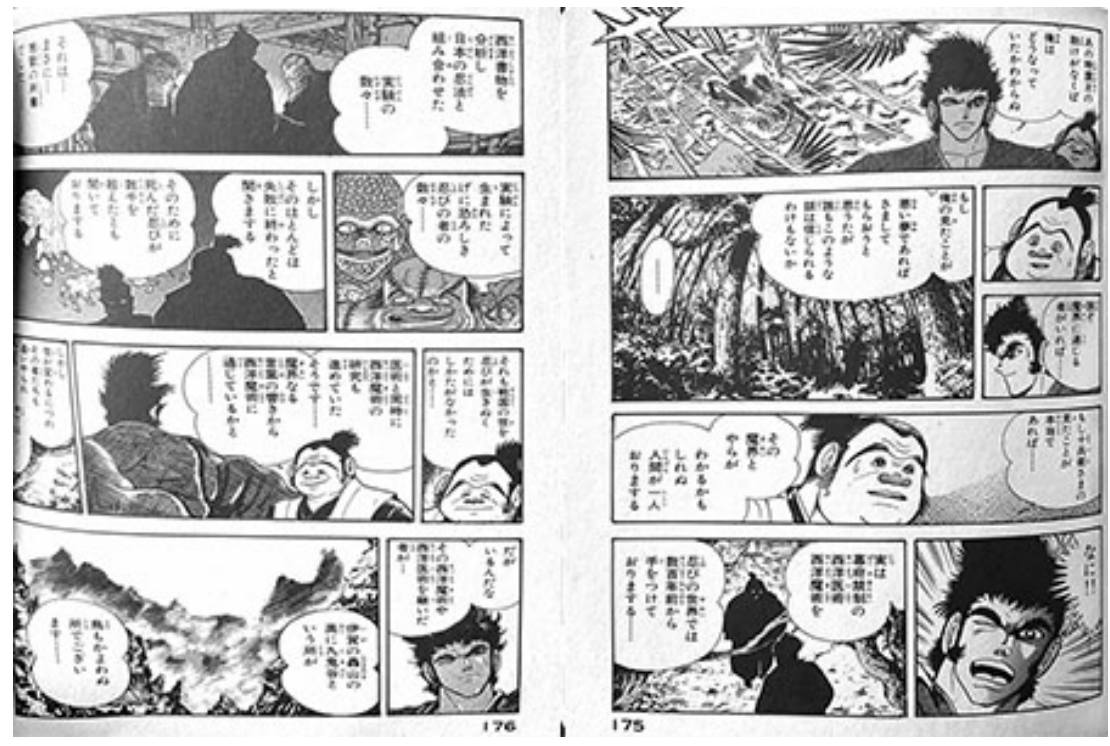

12. Medicina occidental y magia negra (175-176)

Yagyū Jūbei marcha entonces hacia Kukidani, donde encuentra a un grupo de personas con graves deformaciones que han adquirido poderes mágicos como consecuencia de los experimentos a los que los ha sometido una anciana, la experta en medicina occidental y magia negra de la que hablaba el sirviente. Yagyū Jūbei le pregunta a la anciana si sabe algo sobre el infierno (imagen 13):

[256] Anciana: No, no tengo ni idea. He intentado muchas veces descubrir los misterios del infierno. No te imaginas cuánta gente ha muerto en el proceso. He estudiado muchos escritos occidentales sobre exorcismo, adivinación del futuro y magia que llegaron a Japón desde el sudeste de Asia.

La anciana revela que ella es discípula de Mori Soiken, también estudioso de la magia occidental. Recuerda que Mori le pidió años atrás ayuda en un parto; el niño nació a la sexta hora del sexto día del sexto mes. Este niño era Amakusa Shirō, que en este momento aparece mágicamente en la cabaña de la anciana para intentar, una vez más, convencer a Yagyū de que se una a él. Con la ayuda de las víctimas de los experimentos de la anciana, Yagyū se enfrenta a Amakusa Shirō, que queda gravemente herido.
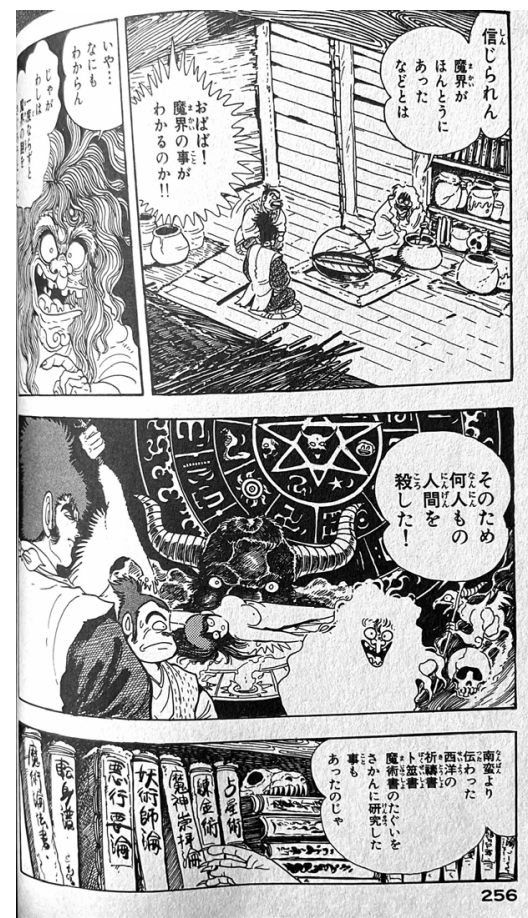

13. Estudios occidentales de la anciana (256) 
Moribundo, consigue reunirse con Mori Soiken, que no se resigna a dejarlo morir, ya que Amakusa «será el emperador del mundo» (365). El anciano se propone realizar en él una segunda makai tenshō, es decir, resucitarlo por segunda vez, para lo cual Amakusa Shirō tiene relaciones sexuales con una mujer que le servirá como receptáculo para su reencarnación. Mori Soiken no está seguro de cuál será el resultado, ya que en sus libros de magia no ha encontrado ninguna referencia a una doble resurrección; sin embargo, sí que recuerda haber leído historias sobre descensos al infierno y resurrecciones (imagen 14):

[406] TOKugaWA YoRINOBu: ¿COnseguirá realmente [Amakusa Shirō] resucitar de nuevo?

[407] MORI SOIKEn: No tengo ni idea. No he leído nada sobre eso en mis libros.

TOKUGAWA YoRINOBu: Aunque consiga resucitar, no sabemos qué forma adoptará. Eso debe ser algo para verlo... je, je, je.

MORI SOIKEN: No bromees. La energía que necesitamos para otra resurrección tendrá que venir de un lugar que no podemos ni tocar.

TAMIYA BOtARO: ¿̇Un lugar que no podemos ni tocar? ¿̇Qué significa eso? MORI SOIKEN: Uno de los libros que he investigado habla de un dios solitario que descendió al mundo de los demonios, y llevó con él una luz tan poderosa que ningún demonio podía acercarse a él, no importa lo poderoso que fuera.

[408] TAMIYA BOTARO: ¿Una luz? ¿̇Eso es lo que pasó?

MORI SOIKEN: Otro libro que leí contenía un relato de un hombre que había resucitado. El hombre se llamaba Jesús, y se dice que salvó a toda la humanidad del infierno.

TOKUGAWA YorINOBU: jJa, ja, ja! Nuestro Shirō no haría algo tan tonto como eso. Ese chico nació para crear el caos en el este mundo. De ninguna manera podría llegar al reino de los dioses.

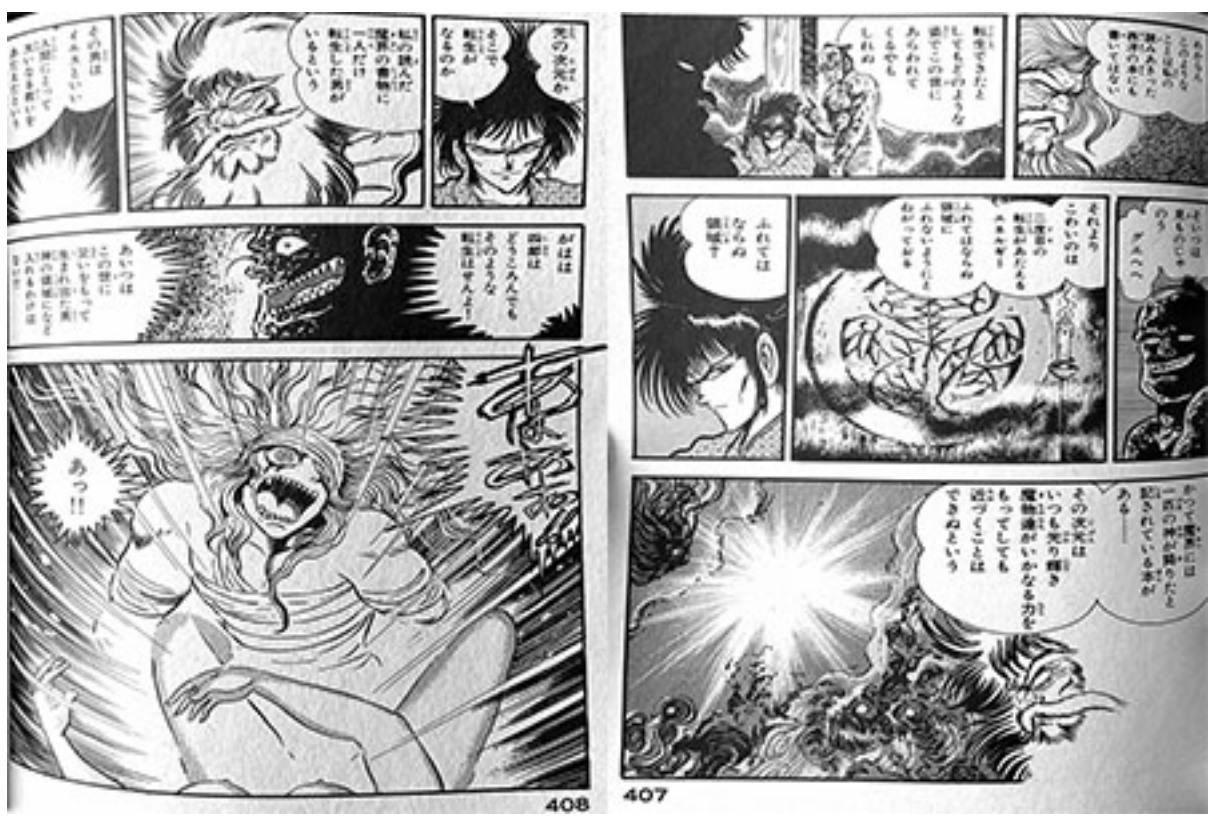

14. Mori Soiken habla de Lucifer y de Jesús (407-408) 
Entre los libros de magia occidentales de Mori Soiken había entonces libros cristianos, o al menos con referencias al cristianismo. Interpreto que el dios que descendió al infierno con una poderosa luz es una referencia a Lucifer basándose en su etimología (lux, 'luz', y ferō, 'llevar'). La asociación de Amakusa Shirō con Jesucristo y su identificación como anti-Cristo -nacido en la sexta hora del sexto día del sexto mes- es evidente en este pasaje. Algo más tarde, mientras espera su reencarnación, Mori Soiken insiste en esta idea al señalar la importancia de Amakusa Shirō en su proyecto de dominación mundial (imagen 15):

[443] MORI SOIKen: Shirō... es especial para mí. Fue un niño demonio, nacido bajo una estrella aciaga. Sin él el mundo de los demonios seguiría siendo un misterio para nosotros. Y cuando este mundo se convierta en parte del infierno, seguiremos necesitándolo. Cuando Satán descienda, la superficie de la tierra será arrasada. Ningún mortal podrá controlar su poder. Por eso necesitamos a Shirō. Él es el niño demonio elegido por el infierno para controlar el poder de Satán.

Mientras todo esto ocurre, Yagyū Jūbei se dirige al castillo donde se encuentran los rebeldes para acabar con ellos. Por el camino se enfrenta y mata sucesivamente a Araki Mataemon, a Hozoin Inshun y a Tamiya Botaro. Cuando llega al castillo, se encuentra con Tokugawa Yorinobu y Mori Soiken, que ha abierto un portal para comunicar el mundo con el infierno y permitir así la entrada a los demonios y a Satán. Sin embargo, sus planes se ven frustrados por Yagyū Jūbei, que mata a Tokugawa Yorinobu, a Miyamoto Musashi y a Mori Soiken y consigue cerrar el portal. El final de la obra se sitúa días después, cuando Yagyū Jūbei se cruza con una joven que lo mira de forma extraña. Como Yagyū Jūbei entiende inmediatamente, se trata de la joven que ha estado incubando a Amakusa Shirō. En las dos últimas páginas del manga vemos cómo el cuerpo de la joven se empieza a desgarrar, del mismo modo que habíamos visto al principio de

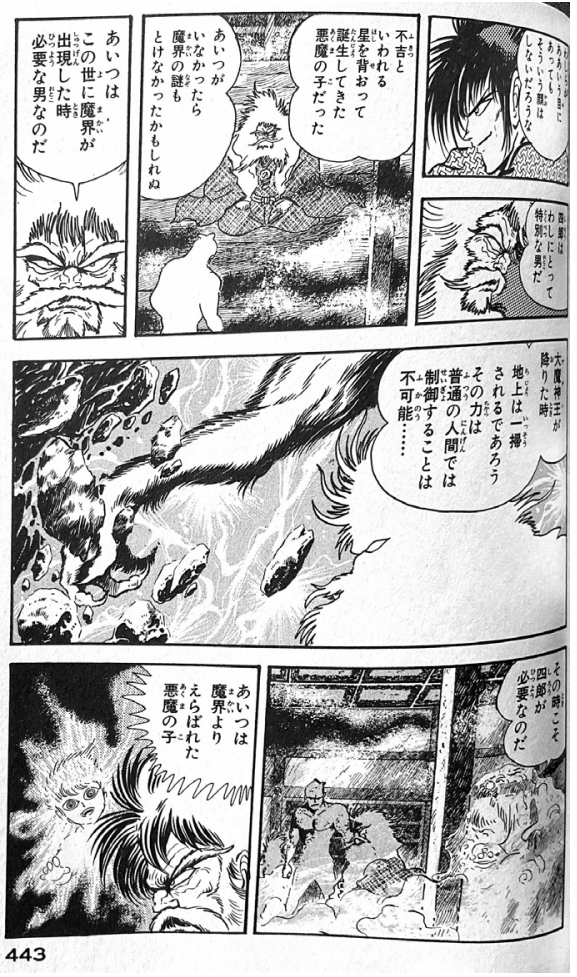

15. Amakusa Shirō, niño demonio elegido por el infierno (443) la obra, y entendemos que de ahí surgirá el doblemente resucitado Amakusa Shirō dispuesto a enfrentarse una vez más con Yagyū Jūbei (imagen 16). 

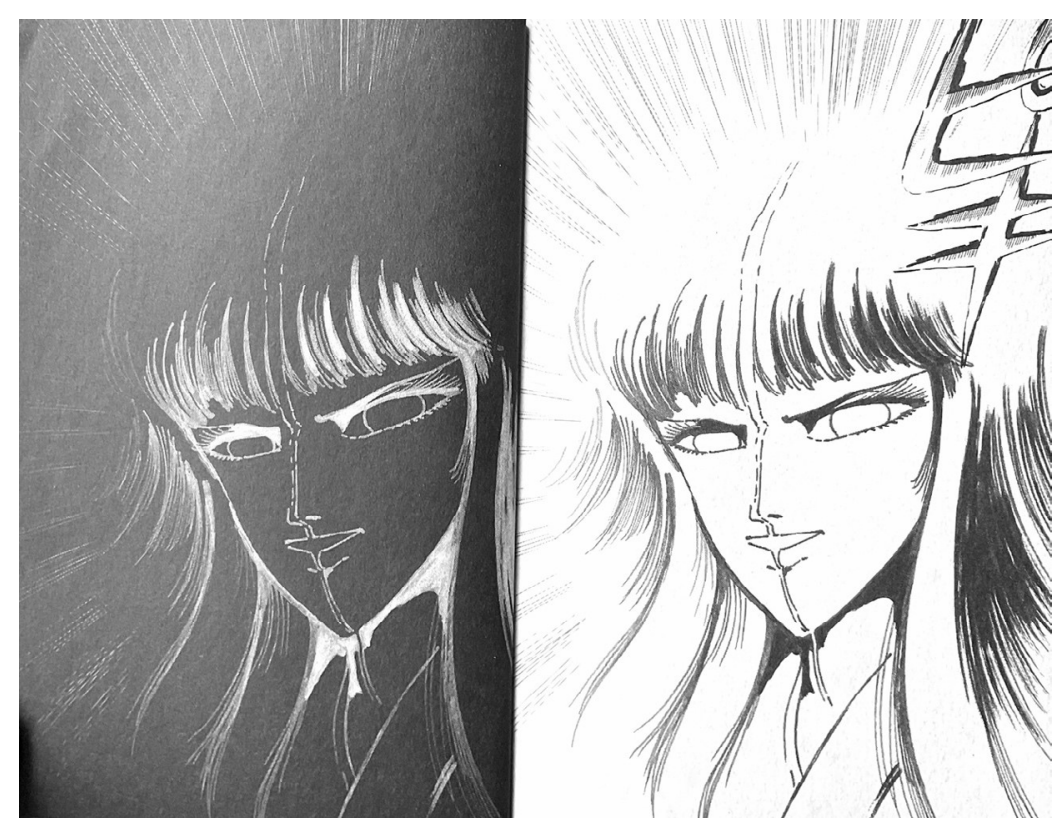

16. Últimas páginas de Makai tenshō: segunda reencarnación de Amakusa Shirō (556-557)

\section{Conclusiones}

La exposición del contenido del manga Makai tenshō en las páginas anteriores revela claramente la influencia que, de manera consciente 0 inconsciente, tuvieron en su composición las antiguas narrativas anticristianas que hemos revisado en el segundo apartado del trabajo. En primer lugar, la invasión de Japón ambicionada por Satán, el rey del mundo de los demonios, y sus seguidores, es un obvio trasunto de la imaginada invasión que los nanban del siglo cristiano habían planeado. Como en el caso de otros autores japoneses del siglo XX (Suter, 2015: 128), aquí también el Dios cristiano y el Diablo cristiano se fusionan como representantes de la misma religión extranjera. Para conseguir hacerse con el poder en Japón, los seguidores de esta religión deben, de manera muy literal, convertir a los japoneses para facilitar la llegada de los demonios y de su rey, Satán, que se debe realizar a través de la creación de un portal mágico que comunique el reino de los demonios, es decir, el infierno, con Japón. Una vez expedita la entrada de los demonios y de Satán a Japón, el país caerá en el caos y pasará a formar parte del infierno.

La conversión en satanista, como el mismo Amakusa Shirō se define, va acompañada de una monstruosa transformación física con la que los conversos abandonan su naturaleza humana para abrazar la demoníaca, que se manifiesta en atributos zoomórficos asociados con Satán, como los cuernos o las pezuñas. Estos conversos son convencidos por los misioneros de Satán con la promesa de la vida eterna, no en el cielo, sino en el infierno en el que Japón se ha de convertir, y con la adquisición de poderes mágicos, como la capacidad de volar, el desplazamiento instantáneo o la fuerza sobrehumana. La única estudiosa de la medicina y la magia occidental que ha sobrevivido a la persecución del shogunato —además del instigador de toda la rebelión 
satánica, su maestro Mori Soiken - vive en lo alto de una montaña como los yamabushi, y también somete a transformaciones físicas a las víctimas de sus experimentos, que resultan gravemente deformados, igualmente, como los misioneros en Kirishitan shūmon raichō jikki, a cambio de poderes mágicos.

En definitiva, el manga Makai tenshō es una obra representativa de la imagen del siglo cristiano en la segunda mitad del siglo XX, en la que, como en la época Edo, se demoniza - literal y figuradamente-la figura del cristiano a través de la asociación con las prácticas mágicas y con la deformación física y moral. El siglo cristiano, la Rebelión de Shimabara y la figura de Amakusa Shirō son tomados como epítome de la amenaza a la homogeneidad cultural japonesa que suponía la apertura al extranjero, en un periodo en el que el manga seinen se asocia más estrechamente con el discurso nacionalista y conservador imperante en algunos sectores de la sociedad japonesa. 


\section{Bibliografía}

BOXER, Charles Ralph (1951), The Christian Century in Japan, 1549-1650, Berkeley-Los Angeles, University of California Press.

Cabezas, Antonio (1995), El siglo ibérico de Japón. La presencia hispanoportuguesa en Japón (1543-1643), Valladolid, Universidad de Valladolid.

ELISON, George (1988), Deus Destroyed. The Image of Christianity in Early Modern Japan, Cambridge (Mass.)Londres, Harvard University Press.

HIGASHIBABA, IkUo (2001), Christianity in Early Modern Japan. Kirishitan Belief and Practice, Leiden-Boston-Colonia, Brill.

IsHIKAWA, Ken (1987), Makai tenshō, Tokio, Yamato Comics. [Reimpr.: 1998, 2005]

LeUCHTENBERGER, Jan C. (2013), Conquering Demons. The "Kirishitan", Japan, and the World in Early Modern Japanese Literature, Ann Arbor, The University of Michigan.

MORLEY, Carolyn Anne (1993), Transformation, Miracles, and Mischief: The Mountain Priest Plays of Kyōgen, Ithaca, Cornell University.
MorrIs, Ivan (2013/1975), The Nobility of Failure. Tragic Heroes in the History of Japan, Tokio, Kurodahan Press.

OtA, Yuzo (2000), "Christianity, Christian Missionaries, and the Image of Westerners in Modern Japanese Literaturel, en Images of Westerners in Chinese and Japanese Literature, Hua Meng y Sukehiro Hirakawa (eds.), Amsterdam, Rodopi, pp. 163-177.

Ruiz-De-Medina, Juan (1990), Documentos del Japón, 1547-1557, Roma, Instituto Histórico de la Compañía de Jesús.

SteVenson, Barbara (2010), «Japan, Medieval», en Handbook of Medieval Studies. Terms - Methods - Trends, Albrecht Classen (ed.), Berlín-Nueva York, De Gruyter, 2010, I, pp. 749-756.

Suter, Rebecca (2015), Holy Ghosts. The Christian Century in Modern Japanese Fiction, Honolulu, University of Hawai'i Press.

ÜÇERLER, M. Antoni J. (2018), "The Christian Missions in Japan in the Early Modern Period», en A Companion to the Early Modern Catholic Global Missions, Ronnie Po-Chia Hsia (ed.), Leiden-Boston-Colonia, Brill, pp. 303343.

Yamada, Fūtarō (1967), Makai tenshō, Tokio, Kodokawa bunko. 


\author{
DoÑAs, Antonio, «Amakusa Shirō, la Rebelión de Shimabara \\ y el cristianismo en el manga Makai tenshō (1987)», Storyca \\ 3 (2021), pp. 55-78.
}

https://doi.org/10.51863/Storyca.2021.Donas

\title{
Resumen
}

El objetivo del presente trabajo es examinar la imagen del cristianismo en el manga de Ishikawa Ken Makai tenshō (1987), adaptación libre de la novela de ficción histórica del mismo nombre compuesta en 1967 por Yamada Fūtarō. Ambientado a finales del Japón medieval, tiene como punto de partida un famoso acontecimiento en la historia del archipiélago, la Rebelión de Shimabara, que puso punto final al llamado "siglo cristiano» de Japón. Uno de los protagonistas de la obra es el líder de esa rebelión, el joven cristiano Amakusa Shirō, convertido en los últimos decenios en un personaje habitual en la cultura de consumo popular japonesa. La representación del cristianismo en Makai tenshō, que se publicó en un periodo de fuerte presencia de nacionalismo japonés en el manga seinen, recoge algunos elementos de la imagen de los misioneros cristianos desarrollada en el Periodo Edo; entre otros, la naturaleza demoniaca de los misioneros, su asociación con la magia y la medicina y su objetivo, frustrado por Tokugawa leyasu, de invadir y someter Japón.

\section{Abstract}

The aim of this paper is to examine the image of Christianity in Ishikawa Ken's manga Makai Tenshō (1987), adapted freely from Yamada Fütarō's historic fiction novel of the same name published in 1967. The manga is set at the end of Japan's medieval period, beginning with a famous event in Japanese history, the Shimabara Rebellion, which is considered the end of the "Christian Century» of Japan. One of the main characters of the work is the leader of that rebellion, Amakusa Shirō, a frequent character in recent Japanese pop culture. The representation of Christianity in Makai

\section{Palabras clave}

Japón

Cristianismo

Misioneros cristianos

Manga

Rebelión de Shimabara

Amakusa Shirō

Ishikawa Ken

Makai tenshō

\section{KeyWords}

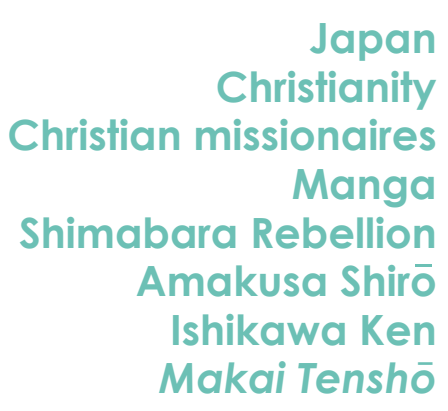


Tenshō, published in a period of strong influence of Japanese nationalism in seinen manga, derives partly from some characteristics of the image of the Christian missionaries developed in Edo Period; among others, their demonic nature, their association with magic and medicine, and their intention, frustrated by Tokugawa leyasu, of invading and subduing Japan. 